\title{
Effectiveness of Protocolized Sedation Utilizing the COMFORT-B Scale in Mechanically Ventilated Children in a Pediatric Intensive Care Unit
}

\author{
Kantara Saelim ${ }^{1}$ Shevachut Chavananon ${ }^{1}$ Kanokpan Ruangnapa ${ }^{1}$ Pharsai Prasertsan ${ }^{1}$ \\ Wanaporn Anuntaseree ${ }^{1}$
}

${ }^{1}$ Department of Pediatrics, Faculty of Medicine, Prince of Songkla University, Songkla, Thailand

J Pediatr Intensive Care 2019;8:156-163.

Address for correspondence Kantara Saelim, MD, Department of Pediatrics, Faculty of Medicine, Prince of Songkla University, Hat Yai, Songkhla 90110, Thailand (e-mail: kantara.s@email.psu.ac.th).

\begin{abstract}
Keywords

- sedation

- COMFORT-B scale

- pediatric intensive care unit

- mechanical ventilation

Appropriate sedation in mechanically ventilated patients is important to facilitate adequate respiratory support and maintain patient safety. However, the optimal sedation protocol for children is unclear. This study assessed the effectiveness of a sedation protocol utilizing the COMFORT-B sedation scale in reducing the duration of mechanical ventilation in children. This was a nonrandomized prospective cohort study compared with a historical control. The prospective cohort study was conducted between November 2015 and August 2016 and included 58 mechanically ventilated patients admitted to the pediatric intensive care unit (PICU). All patients received protocolized sedation utilizing the COMFORT-B scale, which was assessed every 12 hours after intubation by a single assessor. The prospective data were compared with retrospective data of 58 mechanically ventilated patients who received sedation by usual care from November 2014 to August 2015. Fifty percent of 116 patients were male and the mean age was 22 months (interquartile range [IQR]: 6.6-68.4). Patients in the intervention group showed no difference in the duration of mechanical ventilation (median 4.5 [IQR: 2.2-10.5] vs. 5 [IQR: 3-8.8] days). Also, there were no significant differences in the PICU length of stay (LOS; median 7 vs. 7 days, $p=0.59$ ) and hospital LOS (median 18 vs. 14 days, $p=0.14$ ) between the intervention and control groups. The percentages of sedative drugs, including fentanyl, morphine, and midazolam, in each group were not statistically different. The COMFORT-B scale with protocolized sedation in mechanically ventilated pediatric patients in the PICU did not reduce the duration of mechanical ventilation compared with usual care.
\end{abstract}

\section{Introduction}

One of the most challenging management tasks in a pediatric intensive care unit (PICU) is providing optimum sedation in patients on mechanical ventilation. Sedation is thought to be essential in mechanically ventilated patients to maintain

(1D) Kantara Saelim's ORCID is https://orcid.org/0000-0003-19363357.

received

October 20, 2018

accepted after revision

January 13, 2019

published online

February 15, 2019

patient safety and comfort. Although sedation is a crucial treatment, excessive sedation may adversely affect patient outcomes. ${ }^{1}$ Excessive sedation prolongs mechanical ventilation, ICU length of stay (LOS), and hospital LOS. ${ }^{2}$ Longer mechanical ventilation can predispose to further complications, such as ventilator associated pneumonia (VAP), opioid tolerance, and iatrogenic withdrawal. On the other hand, inadequate sedation and pain control can cause patient discomfort, agitation, and possibly self-extubation. ${ }^{3}$

Copyright (c) 2019 by Georg Thieme Verlag KG, Stuttgart . New York
DOI https://doi.org/ 10.1055/s-0039-1678730. ISSN 2146-4618. 
The assessment of sedation and adjustment of medications are critical for mechanically ventilated children. Several sedation scoring scales have been described in pediatrics, such as the COMFORTscale, Ramsayscale, the sedation-agitation scale, motor activity assessment scale, the state behavioral scale, and face, leg, activity, cry, consolability (FLACC). ${ }^{4,5}$ The COMFORT scale has been validated in pediatrics and is well structured. However, the COMFORT scale has physiologic parameters that are influenced by causes other than the level of sedation. This was subsequently modified into the COMFORT-B scale which uses the behavior of the patient from direct observation. ${ }^{6}$ The COMFORT-B scale is well validated in pediatric and neonatal patients. ${ }^{6}$ and detects treatment-related changes in pain or distress intensity. Therefore, the COMFORT-B scale can effectively assess and guide sedation in pediatric patients who require mechanical ventilation. ${ }^{7}$

There is a limited amount of data on protocol-directed sedation in pediatric patients. ${ }^{8}$ This study compares sedation level assessments by the COMFORT-B scale with a medication adjustment protocol to usual care to assess the reduction of mechanical ventilation days.

\section{Materials and Methods}

\section{Design}

This study was a nonrandomized prospective cohort study compared with a historical control. The study was approved by the institutional board review and Thai Clinical Trials Registry (TCTR; TCTR 20181208001). The sedation levels of the patients in the intervention group were assessed by the COMFORT-B scale and the sedative medications were adjusted according to the newly developed sedation protocol. The control group was assessed and the sedative medications were adjusted by bedside nurses and attending

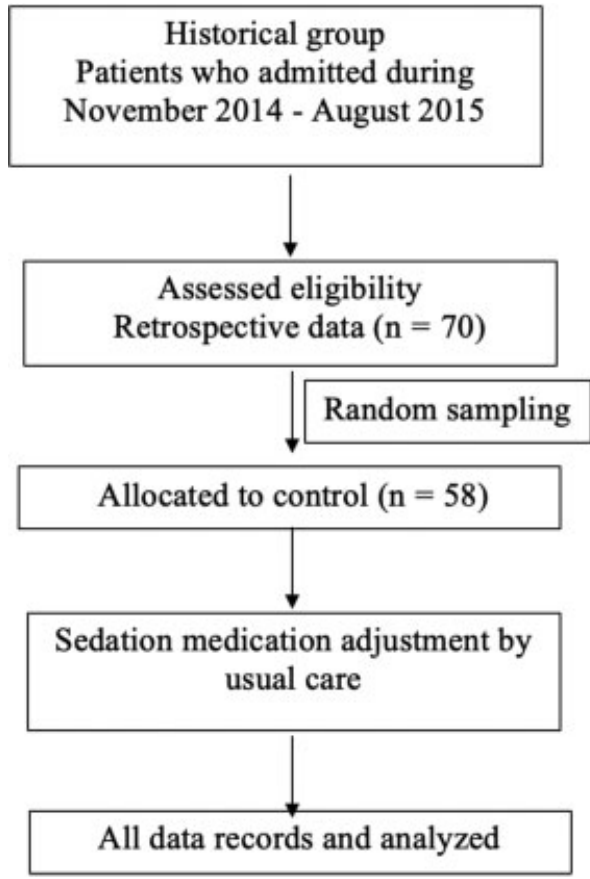

physicians based on clinical judgment (-Fig. 1). The primary outcome of this study was to compare the mechanical ventilation days between the two groups. The secondary outcome was to compare LOS (days) in PICU.

\section{Study Location and Period}

This study was conducted in a tertiary care level PICU at a referral center in southern Thailand. The study periods in the historical group and intervention group were from November 2014 to August 2015 and from November 2015 to August 2016, respectively. Data collection was performed in the same seasonal period for both groups to decrease bias.

\section{Patients}

The inclusion criteria included patients, 1 month to 15 years old, who were admitted to the PICU, intubated, and received sedative medication for at least 48 hours. The exclusion criteria for this study included patients with neurological disease because the level of sedation cannot be assessed by the COMFORT-B scale, patients who received neuromuscular blockade, and patients who needed a very deep sedation level for treatment as in cases of pulmonary hypertensive crisis.

\section{Sample Size Calculation}

From a previous study, assessment using the COMFORT scale could decrease the number of ventilation days by 1.5 days. ${ }^{9}$ We used the two independent means test (twotailed test) and defined the difference to be equal to 2 days. From the calculation, the number of participants in each group was 53 . To compensate for incomplete data, the number of participants was increased by $10 \%$. The total number of participants in each group was 58. In the historical control group, the number of patients admitted to the PICU and eligible for the study was 70. Therefore,

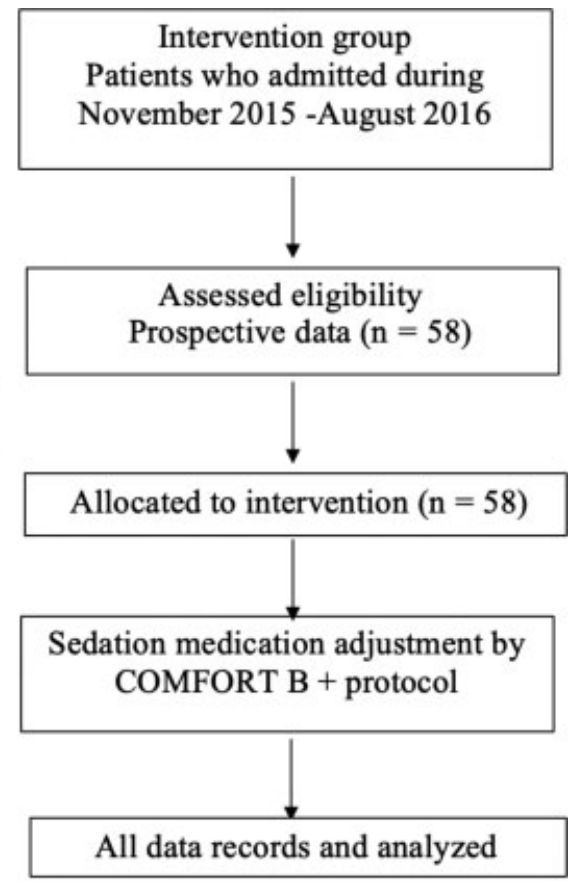

Fig. 1 Diagram of patient flow during study. 
computerized random sampling was done to select the patients for the study.

\section{Intervention and Study Protocol}

The intervention in this study consisted of two main parts. First was the sedation level assessment by COMFORT-B scale and second was the sedative medication adjustment protocol. A newly developed standard and stepwise-approach protocol was used to guide and direct the adjustment of sedative medications. The sedative medication adjustment protocol constituted in three parts: a basic approach, an increasing scheme, and a decreasing scheme (-Figs. 2-4).

After formal consent by the parents or caregivers, the COMFORT-B scale was used in the intervention group to assess the sedation level every 12 hours by a pediatric resident. COMFORT-B levels of 5 to 10 were defined as over sedation, 11 to 22 as optimum sedation, and 23 to 30 as inadequate sedation as previously described. ${ }^{10}$ The sedative medications were adjusted according to the protocol. In our protocol, continuous infusion of an opioid was used as the initial medication. Morphine was the first line medication. However, fentanyl was used instead of morphine in neonates and patients who had liver dysfunction. If the patient had inadequate sedation, the medications were escalated as per the increasing scheme. On the other hand, in patients who were over sedated the medications were weaned per the decreasing scheme. In the historical control group, the sedative medications were adjusted according to

Basic sedative medication adjustment protocol by COMFORT-B scale

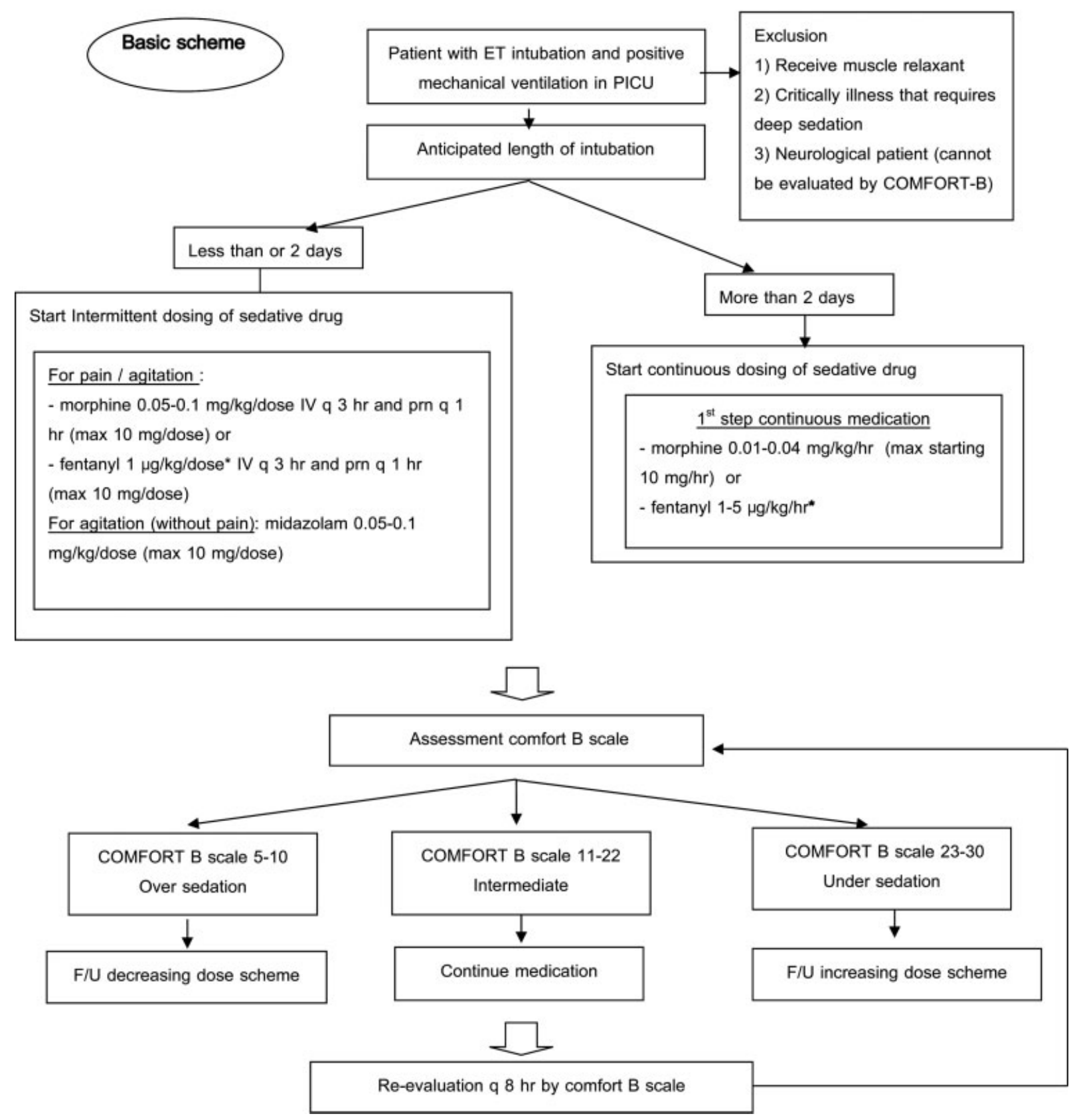

Fig. 2 Basic sedative medication adjustment protocol. PICU, pediatric intensive care unit. ET, endotracheal tube; F/U, follow-up. 

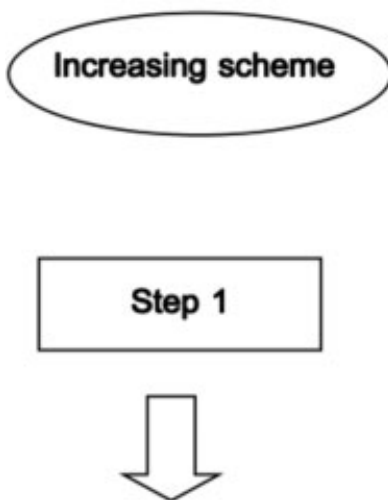<smiles>C1CCCCC1</smiles>

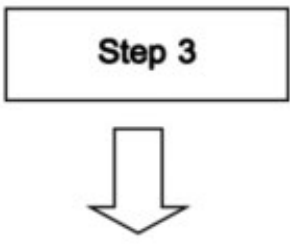

Step 4<smiles>C1CCC2CCCC2C1</smiles>

Step 5

\section{Intermittent dose}

\section{For pain / agitation :}

- morphine $0.05-0.1 \mathrm{mg} / \mathrm{kg} / \mathrm{dose}$ IV q $3 \mathrm{hr}$ and prn q $1 \mathrm{hr}(\max 10$

$\mathrm{mg} / \mathrm{dose}$ ) or

- fentanyl $1 \mu \mathrm{g} / \mathrm{kg} /$ dose $^{*} \mathrm{IV}$ q $3 \mathrm{hr}$ and prn q $1 \mathrm{hr}$

For agitation (without pain): midazolam $0.05-0.1 \mathrm{mg} / \mathrm{kg} / \mathrm{dose}$ ( $\max 10$ $\mathrm{mg} /$ dose)

\section{$\mathbf{1}^{\text {st }}$ step continuous medication}

- morphine $0.01-0.04 \mathrm{mg} / \mathrm{kg} / \mathrm{hr}$ (max starting $10 \mathrm{mg} / \mathrm{hr}$ ) IV continuous drip

or

- fentanyl $1-5 \mu \mathrm{g} / \mathrm{kg} / \mathrm{hr} r^{*} \mathrm{IV}$ continuous drip

\section{$2^{\text {nd }}$ step continuous medication}

- midazolam $1 \mu \mathrm{g} / \mathrm{kg} / \mathrm{min}$ IV continuous drip

\section{Add synergistic oral drug (if not NPO)}

- lorazepam 0.05-0.1 mg/kg/dose PO q 4-8 hr or

- chloral hydrate $50-75 \mathrm{mg} / \mathrm{kg} / \mathrm{dose} \mathrm{PO}$ q 6-12 hr

\section{Tritration medication}

- morphine $0.01-0.04 \mathrm{mg} / \mathrm{kg} / \mathrm{hr}$ IV continuous drip

- fentanyl 1-5 $\mu \mathrm{g} / \mathrm{kg} / \mathrm{hr}$ IV continuous drip

- midazolam 2-10 $\mu \mathrm{g} / \mathrm{kg} / \mathrm{min}$ IV continuous drip

Fig. 3 Increasing scheme of sedative medication adjustment protocol. NPO, not thing per oral.

the nursing assessment and attending physicians only in the morning rounds. The sedation medications were stopped at least 6 hours before extubation in both groups according to the weaning and extubation protocol in the PICU.

\section{Data Collection}

The data of all participants in both groups were extracted from the medical records. Baseline characteristics included age, underlying diseases, other medications (e.g., inotropic drugs and the sedative medications that included continuous infusion form, intravenous [IV] intermittent form, and oral form). Pediatric risk of mortality III (PRISM III) scores were recorded for severity of illness. The dosage of sedative medication and analgesia are presented as $\mathrm{mg} / \mathrm{kg} /$ day for midazolam, morphine, and chloral hydrate and $\mathrm{mcg} / \mathrm{kg} /$ day for fentanyl. The outcomes were duration of mechanical ventilation (days), self-extubation rate, LOS (days) in PICU, hospital LOS (days), and 28-day mortality. 


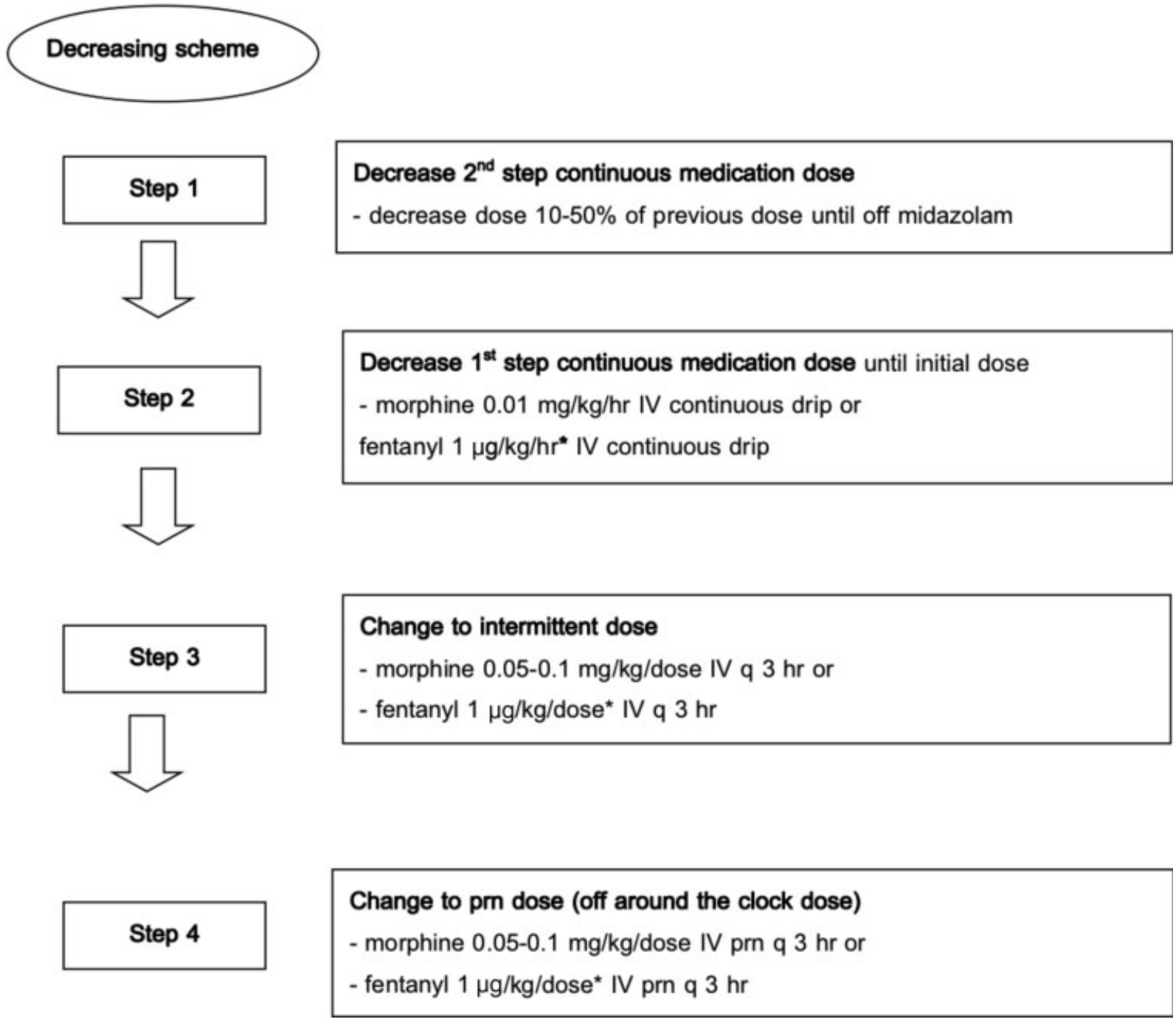

Fig. 4 Decreasing scheme of sedative medication adjustment protocol. "Use fentanyl instead of morphine in newborn and patients with liver dysfunction.

\section{Statistical Analysis}

Mann-Whitney rank sum test was used for continuous data and Chi-square analysis or Fisher's exact test or Pearson's Chisquare test for the discrete data. Data were presented as mean \pm standard deviation (SD) and median with interquartile range (IQR). Clinical significance was determined by $p<0.05$. Spearman's rank correlation coefficient was used to evaluate the correlation of PRISM III and primary outcome. Multiple logistic regression was applied to determine the odds of the primary outcome that depended on covariate variables.

\section{Results}

\section{Patient Characteristics}

The study population included 116 participants, 58 in each group. The baseline characteristics are described in - Table 1 . The overall baseline characteristics, that included age, sex, underlying diseases, and surgical patients, were the same in the two groups. However, the PRISM III scores were higher in the intervention group (median [IQR]: 6.0 [0.2-9.0] vs. 2.5 [0.0-5.0], $p<0.01$ ).

\section{Primary Outcome and Secondary Outcome}

The mean ventilator days in the intervention groups were 4.5 days (IQR: 2.2-10.5) which was not significantly different from the control group of 5.0 days (IQR: 3.0-8.8). The PICU LOS and hospital LOS were the same between the two groups ( - Table 2). There were no significant differences of self-extubation events and 28-day PICU mortality rates between the two groups.

\section{Subgroup Analysis}

Since the nature of the study was nonrandomized prospective cohort study that compared the results with a historical control group, the intervention group had higher PRISM III scores. Spearman's rank correlation coefficient was used to evaluate the correlation of the PRISM III scores and ventilator days. The $\rho$ (Rho) was 0.18 which meant a poor correlation between the PRISM III score and ventilator days. Multiple logistic regression was used to evaluate the factors that possibly affected ventilator days. The median number of ventilator days of all participants was 5 days. Therefore, an outcome of $\geq 5$ ventilator days was used in multiple logistic regression analysis and the results are given in - Table 3 . The 
Table 1 Characteristics and status of patients

\begin{tabular}{|c|c|c|c|c|}
\hline Baseline characteristics & $\begin{array}{l}\text { All patients } \\
n=116\end{array}$ & $\begin{array}{l}\text { Intervention group } \\
n=58\end{array}$ & $\begin{array}{l}\text { Control group } \\
n=58\end{array}$ & p-Value \\
\hline Age (mo), median (IQR) & $22.3(6.6,68.4)$ & $26.8(7.7,90.6)$ & $17.9(5.5,46.2)$ & 0.20 \\
\hline Male & $59(50.8)$ & $27(46.6)$ & $32(55.2)$ & 0.45 \\
\hline \multicolumn{5}{|l|}{ Underlying disease and diagnosis } \\
\hline cardiac diseases & $55(47.4)$ & $25(43.1)$ & $30(51.7)$ & 0.45 \\
\hline hemato-oncology & $20(17.2)$ & $13(22.4)$ & $7(12.1)$ & 0.21 \\
\hline pneumonia & $17(14.6)$ & $3(5.2)$ & $14(24.1)$ & $<0.01$ \\
\hline PRISM III score ${ }^{a}$, median (IQR) & $4.25(0.1,7.0)$ & $6.0(0.2,9.0)$ & $2.5(0.0,5.0)$ & $<0.01$ \\
\hline Inotropic score, median (IQR) & $20(0,73.8)$ & $15(0,67.5)$ & $20(0,70.8)$ & 0.76 \\
\hline Postoperative patients & $64(55.1)$ & $31(53.4)$ & $33(56.9)$ & 0.85 \\
\hline
\end{tabular}

Abbreviations: IQR, interquartile range; PICU, pediatric intensive care unit.

Note: Data are presented as $\mathrm{n}(\%)$ unless indicated otherwise.

aPRISM III: pediatric risk of mortality III score at PICU admission.

Table 2 Outcomes of the study

\begin{tabular}{|l|l|l|l|}
\hline Outcome & $\begin{array}{l}\text { Intervention group } \\
(\boldsymbol{n}=58)\end{array}$ & $\begin{array}{l}\text { Control group } \\
(\boldsymbol{n}=\mathbf{5 8})\end{array}$ & 5 -Value \\
\hline Mechanical ventilation (d), median (IQR) & $4.5(2.2,10.5)$ & $7(4.0,8.8)$ & 0.83 \\
\hline PICU LOS (d), median (IQR) & $7(4.0,16.2)$ & $14(10.0,28.0)$ & 0.59 \\
\hline Hospital LOS (d), median (IQR) & $18(11.2,35.8)$ & $2(3.4)$ & 0.14 \\
\hline Self-extubation (episodes) & $1(1.7)$ & & 1.00 \\
\hline PICU discharge status & & $5(8.6)$ & \\
\hline 28 d-mortality & $9(15.5)$ & $50(86.2)$ & 0.12 \\
\hline Survived & $49(84.5)$ & $3(5.2)$ & 0.85 \\
\hline Transferred to another hospital & $0(0.0)$ & 0.14 \\
\hline
\end{tabular}

Abbreviations: IQR, interquartile range; LOS, length of stay; PICU, pediatric intensive care unit.

Note: Data are presented as $n(\%)$ unless indicated otherwise.

Table 3 Multiple logistic regression analysis to predict ventilator days $\geq 5$ days

\begin{tabular}{|l|l|l|l|}
\hline & $\begin{array}{l}\text { Crude OR } \\
(95 \% \mathrm{CI})\end{array}$ & $\begin{array}{l}\text { aOR } \\
(95 \% \mathrm{CI})\end{array}$ & $p$-Value \\
\hline PRISM III scores & $1.1(1-1.21)$ & $1.11(1-1.23)$ & 0.05 \\
\hline Medical illness & $\begin{array}{l}3.65 \\
(1.67-7.94)\end{array}$ & $\begin{array}{l}3.39 \\
(1.53-7.49)\end{array}$ & $<0.05$ \\
\hline $\begin{array}{l}\text { Usual sedation } \\
\text { adjustment }\end{array}$ & $\begin{array}{l}1.19 \\
(0.57-2.47)\end{array}$ & $\begin{array}{l}1.64 \\
(0.71-3.78)\end{array}$ & 0.242 \\
\hline
\end{tabular}

Abbreviations: aOR, adjusted odds ratio; $\mathrm{Cl}$, confidence interval; PRISM III: pediatric risk of mortality III.

only factors that had an effect on ventilator days were medical or surgical conditions. The medical patients had an adjusted odds ratio of prolonged mechanical ventilation ( $\geq 5$ days) equal to 3.39 (range: $1.53-7.49$ ), $p<0.05$. So, the subgroup analysis was conducted to determine the effect of intervention. In patients with medical illness, the PRISM III scores were significantly higher in the intervention group but the ventilator days were not significantly different. In
Table 4 Subgroup analysis

\begin{tabular}{|c|l|l|l|}
\hline & $\begin{array}{l}\text { Intervention } \\
\text { group }\end{array}$ & $\begin{array}{l}\text { Control } \\
\text { group }\end{array}$ & $p$-Value \\
\hline Medical diseases & $n=27$ & $n=25$ & $<0.05$ \\
\hline $\begin{array}{c}\text { PRISM III score } \\
\text { (mean, SD) }\end{array}$ & $7.4(4.9)$ & $3.1(3.1)$ & \\
\hline $\begin{array}{l}\text { Ventilator days } \\
\text { (median, IQR) }\end{array}$ & $6(4,12)$ & $7(5,10)$ & 0.80 \\
\hline Postoperative & $n=31$ & $n=33$ & \\
\hline $\begin{array}{c}\text { PRISM III } \\
\text { (median, IQR) }\end{array}$ & $5(0,7)$ & $3(0,6)$ & 0.29 \\
\hline Ventilator days & $3(2,8.5)$ & $4(2,7)$ & 0.92 \\
\hline
\end{tabular}

Abbreviations: IQR, interquartile range; PRISM III: pediatric risk of mortality III; SD, standard deviation.

Note: Data are presented as median (IQR) except in PRISM III score in medical diseases which present as mean, SD.

patients with postoperative conditions, the PRISM III scores and ventilator days were not significantly different between the two groups ( - Table 4 ). 


\section{Number of patients who received sedative medications}

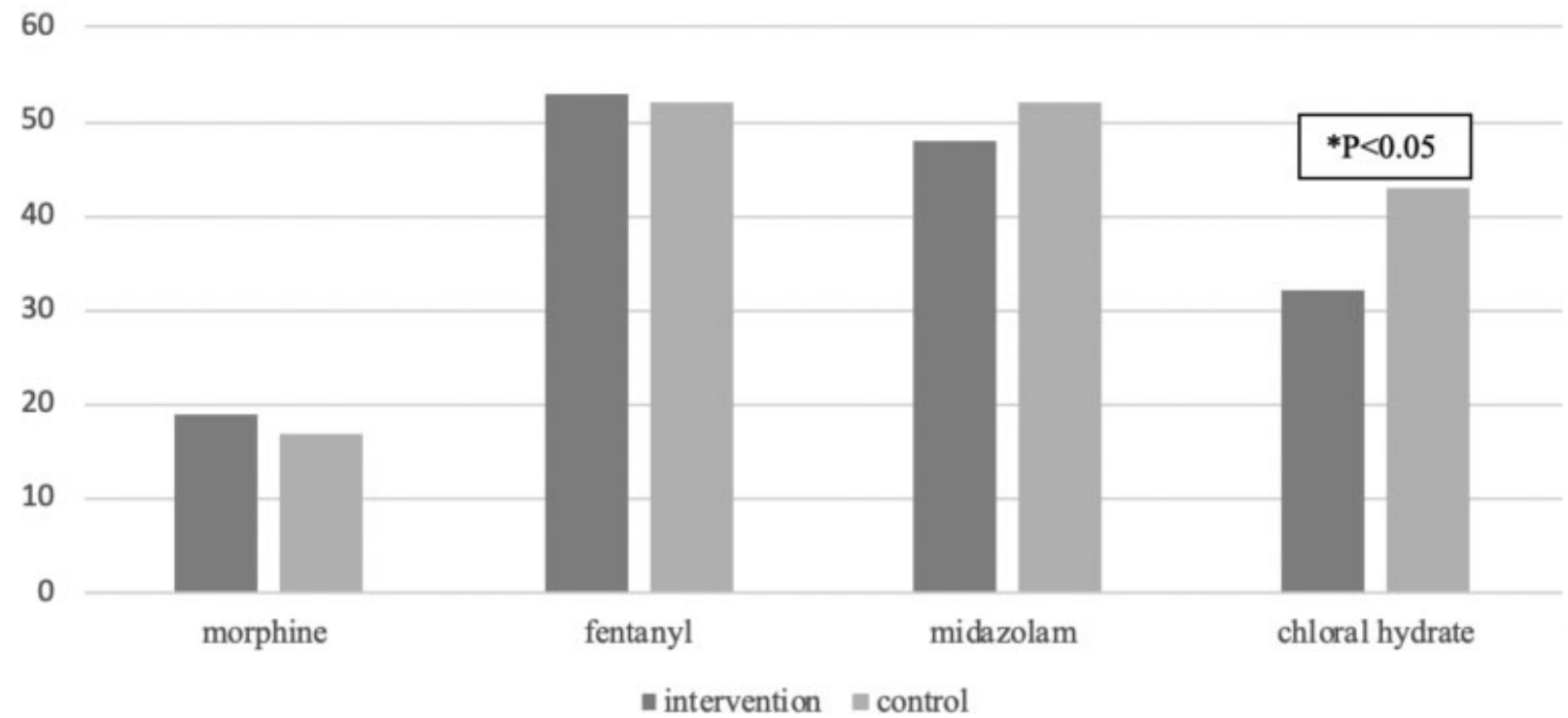

Fig. 5 Numbers of patients who received sedative medications. "Use fentanyl instead of morphine in newborn and patients with liver dysfunction.

Table 5 Cumulative dosage of sedative medications

\begin{tabular}{|l|l|l|l|}
\hline $\begin{array}{l}\text { Sedative } \\
\text { medications }\end{array}$ & $\begin{array}{l}\text { Intervention } \\
\text { group } \\
(\boldsymbol{n}=\mathbf{5 8})\end{array}$ & $\begin{array}{l}\text { Control } \\
\text { group } \\
(\boldsymbol{n}=58)\end{array}$ & $p$-Value \\
\hline $\begin{array}{l}\text { Morphine dose } \\
(\mathrm{mg} / \mathrm{kg} / \mathrm{d})\end{array}$ & $0(0-0.3)$ & $0(0-0.1)$ & 0.49 \\
\hline $\begin{array}{l}\text { Fentanyl dose } \\
(\mathrm{mcg} / \mathrm{kg} / \mathrm{d})\end{array}$ & $\begin{array}{l}5.3 \\
(1.2-26.7)\end{array}$ & $\begin{array}{l}3.4 \\
(1.6-22.7)\end{array}$ & 0.42 \\
\hline $\begin{array}{l}\text { Midazolam dose } \\
(\mathrm{mg} / \mathrm{kg} / \mathrm{d})\end{array}$ & $\begin{array}{l}0.2 \\
(0.1-1.5)\end{array}$ & $\begin{array}{l}0.3 \\
(0.1-2.4)\end{array}$ & 0.23 \\
\hline $\begin{array}{l}\text { Chloral hydrate } \\
\text { dose }(\mathrm{mg} / \mathrm{kg} / \mathrm{d})\end{array}$ & $\begin{array}{l}15.7 \\
(0-42.8)\end{array}$ & $\begin{array}{l}40.9 \\
(2.8-64.4)\end{array}$ & $<0.05$ \\
\hline
\end{tabular}

Note: Data are presented as median (interquartile range [IQR]).

\section{Medication Usage}

In terms of medication usage, the number of patients that received each medication and the cumulative doses during the hospital stay were recorded. The numbers of patients who received sedative medication (-Fig. 5) and the cumulative dosages (-Table 5 ) were not significantly different between the intervention and control groups with the exception of chloral hydrate. The percentage of patients who received chloral hydrate as an adjunctive medication and the cumulative dose $(\mathrm{mg} / \mathrm{kg} /$ day) were significantly lower in the intervention group ( 55 vs. $74 \%, p=0.05$ and 15.7 [IQR: 0-42.8] vs. 40.9 [IQR: 2.8-64.4] $\mathrm{mg} / \mathrm{kg} / \mathrm{day}$, $p=0.002$ ).

\section{Discussion}

From our study, protocolized sedation utilizing the COMFORT-B scale did not significantly reduce mechanical ventilation days compared with usual care. This finding was also seen in recent studies on sedation protocols in mechanically ventilated patients. ${ }^{11-13}$ There were multiple factors that affected the duration of mechanical ventilation, especially the severity of illness. In our study, the intervention group had higher PRISM III scores which reflected sicker participants. However, the PRISM III scores were poorly correlated with ventilator days in the secondary analysis. The frequency of assessment also possibly played a role in medication adjustment. In our study, the assessment was done routinely every 12 hours and when necessary. Most participants in the intervention group had adequate sedation and rarely needed adjustment. The frequency of assessment was also the same in the historical control group. Multiple logistic regression analysis showed that the only factor that contributed to ventilator days was medical illness. Medical patients had longer duration of mechanical ventilation and LOS in PICU due to the complexities and treatments of the diseases. Consequently, the application of the same optimum goal of sedation level may not be suitable in all patients. The sedation level may need adjustment according to the phase of illness and the individual patient. The other possible cause of no significant reduction in duration of mechanical ventilation was the small number of patients. Furthermore, the previous study, showing that adjusting sedation medications by using the COMFORT scale could decrease ventilator days by 1.5 days, ${ }^{9}$ did not describe how to adjust the medications.

This study also explored the rate of self-extubation and the total amount of sedative medication usage as a secondary outcome in the PICU. However, the number of self-extubation episodes was too low to compare between the two groups. There was no significant increase in the use of fentanyl and morphine since an opioid is the first line medication in our protocol. A significant reduction was observed in the number of patients in the intervention group who received chloral hydrate and in the total amounts of this medication after using 
the protocol, since chloral hydrate was used as an adjunctive medication.

According to the treatment protocol, the management guideline and treatment protocols varied which depended on the center. ${ }^{14-16}$ We developed a well-structured design for treatment that consisted of a basic scheme, a decreasing scheme, and an increasing scheme. So, in terms of generalizability, this protocol can be applied and may have benefit in a developing unit. In our historical controlled group, the sedation levels were done by experienced nurses and the results between the two groups were not statistically different. In addition, we assumed that in a stepwise approach to decrease or increase medication, the rate of iatrogenic withdrawal symptoms would decrease. ${ }^{17}$

To our knowledge, this is the first study to conduct an assessment of the COMFORT-B scale with a sedative medication adjustment protocol. Moreover, in our study, the COMFORT-B assessor was a pediatric resident, who was well trained and had good knowledge of the interpretation of the COMFORT-B scale. However, a limitation is the prospective cohort study design compared with a historical control. Furthermore, our study was a single unit study with a small number of patients and some data were not available, especially iatrogenic withdrawal symptoms.

\section{Conflict of Interest}

None declared.

\section{References}

1 Tobias JD. Tolerance, withdrawal, and physical dependency after long-term sedation and analgesia of children in the pediatric intensive care unit. Crit Care Med 2000;28(06):2122-2132

2 Vet NJ, Ista E, de Wildt SN, van Dijk M, Tibboel D, de Hoog M. Optimal sedation in pediatric intensive care patients: a systematic review. Intensive Care Med 2013;39(09):1524-1534

3 Hogarth DK, Hall J. Management of sedation in mechanically ventilated patients. Curr Opin Crit Care 2004;10(01):40-46

4 De Jonghe B, Cook D, Appere-De-Vecchi C, Guyatt G, Meade M, Outin $\mathrm{H}$. Using and understanding sedation scoring systems: a systematic review. Intensive Care Med 2000;26(03):275-285

5 Harris J, Ramelet AS, van Dijk M, et al. Clinical recommendations for pain, sedation, withdrawal and delirium assessment in critically ill infants and children: an ESPNIC position statement for healthcare professionals. Intensive Care Med 2016;42(06):972-986

6 van Dijk M, Peters JW, van Deventer P, Tibboel D. The COMFORT Behavior Scale: a tool for assessing pain and sedation in infants. Am J Nurs 2005;105(01):33-36

7 Boerlage AA, Ista E, Duivenvoorden HJ, de Wildt SN, Tibboel D, van Dijk M. The COMFORT behaviour scale detects clinically meaningful effects of analgesic and sedative treatment. Eur J Pain 2015; 19(04):473-479

8 Aitken LM, Bucknall T, Kent B, Mitchell M, Burmeister E, Keogh SJ. Protocol-directed sedation versus non-protocol-directed sedation to reduce duration of mechanical ventilation in mechanically ventilated intensive care patients. Cochrane Database Syst Rev 2015;1:CD009771

9 Jin HS, Yum MS, Kim SL, et al. The efficacy of the COMFORT scale in assessing optimal sedation in critically ill children requiring mechanical ventilation. J Korean Med Sci 2007;22(04):693-697

10 Ista E, van Dijk M, Tibboel D, de Hoog M. Assessment of sedation levels in pediatric intensive care patients can be improved by using the COMFORT “behavior" scale. Pediatr Crit Care Med 2005; 6(01):58-63

11 Deeter KH, King MA, Ridling D, Irby GL, Lynn AM, Zimmerman JJ. Successful implementation of a pediatric sedation protocol for mechanically ventilated patients. Crit Care Med 2011;39(04): 683-688

12 Curley MA, Wypij D, Watson RS, et al; RESTORE Study Investigators and the Pediatric Acute Lung Injury and Sepsis Investigators Network. Protocolized sedation vs usual care in pediatric patients mechanically ventilated for acute respiratory failure: a randomized clinical trial. JAMA 2015;313(04):379-389

13 Keogh SJ, Long DA, Horn DV. Practice guidelines for sedation and analgesia management of critically ill children: a pilot study evaluating guideline impact and feasibility in the PICU. BMJ Open 2015;5(03):e006428

14 Zeilmaker-Roest GA, Wildschut ED, van Dijk M, et al; Paediatric Analgesia after Cardiac Surgery consortium. An international survey of management of pain and sedation after paediatric cardiac surgery. BMJ Paediatr Open 2017;1(01):e000046

15 Hartman ME, McCrory DC, Schulman SR. Efficacy of sedation regimens to facilitate mechanical ventilation in the pediatric intensive care unit: a systematic review. Pediatr Crit Care Med 2009;10(02):246-255

16 Dreyfus L, Javouhey E, Denis A, Touzet S, Bordet F. Implementation and evaluation of a paediatric nurse-driven sedation protocol in a paediatric intensive care unit. Ann Intensive Care 2017;7(01):36

17 Vet NJ, Kleiber N, Ista E, de Hoog M, de Wildt SN. Sedation in critically Ill children with respiratory failure. Front Pediatr 2016;4:89 